\title{
Effects of Different Thermoplastic Wax-based Binders on Properties of 316L Stainless Steel Injection Molding Parts
}

\author{
Dou Yakun, Feng Yi, Huang Xiaochen, Tang Hai, Ding Dongdong, Tian Pei, \\ Xia Meng, Qian Gang, Zhang Xuebin
}

Hefei University of Technology, Hefei 230009, China

\begin{abstract}
A thorough understanding of thermoplastic polymer in the wax-based binder is essential for ensuring the dimensions and mechanical properties of $316 \mathrm{~L}$ stainless steel metal injection molding parts. The effects of three thermoplastic polymers, high density polyethylene, high density polyethylene/polypropylene and polypropylene, on the dimensions and mechanical properties of $316 \mathrm{~L}$ stainless steel metal injection molding parts have been compared. The tensile bars were tested to examine the dimensions and mechanical properties of sintered parts against different thermoplastic polymers in the binder. Among the three thermoplastic polymers in the binder considered herein, high density polyethylene/polypropylene performs better than others in solvent debinding stage and in terms of the metal injection molding compact quality. High density polyethylene/polypropylene has significantly increases the stabilities of length, width and thickness by up to $46 \%, 40 \%, 20 \%$, respectively. The density, hardness and tensile strength of the sintered parts are $7.28 \mathrm{~g} / \mathrm{cm}^{3}, 72.3 \mathrm{HRB}$ and $579 \mathrm{Mpa}$, respectively.
\end{abstract}

Key words: Thermoplastic; Metal injection molding; 316L stainless steel; Mechanical properties

Metal injection molding (MIM) has rapidly increased in recent years due to the increasing demand in various applications fields, such as sensors, medical and energy devices. It is a near net-shape molding process that combines the advantages of plastic injection molding and powder metallurgy procedures ${ }^{[1-3]}$. MIM comprises four sequential stages: (1) blending metallic powders and binders to get the feedstock, (2) injecting feedstock into the mold to get the green parts, (3) solvent or thermal debinding to eliminate the binders used to provide the powder with fluidity during the injection molding stage, and (4) sintering by solid state diffusion to get dense metallic components ${ }^{[4]}$. Feedstock is critically important to MIM; in particular, the binders in the feedstocks strongly determine MIM quality.

The binders transport the powdered particles during the injection molding stage and improve the mechanical properties of feedstock, and prevent separation phenomena between binders and powders. It also strongly influences the maximum solids fraction of the mixture that can be molded, the strength of the green parts, the dimensions and mechanical properties of the final products. However, the performance of binders mainly depends on the content of the backbone polymer ${ }^{[5]}$, which determines the strength of green parts in the injection molding stage and maintains the shape of the compact in the debinding stage. High density polyethylene (HDPE) and polypropylene (PP) are commonly used backbone polymers in the MIM process that are favorable for injection molding, which have different influences on the MIM process. Many former works in this field mainly concentrated on the settings of the powder loading, blending, debinding, injection process parameters, and sintering process parameters ${ }^{[6-11]}$. However, the effects of HDPE, HDPE/PP, PP backbone polymers on MIM parts were rarely studied. Therefore, this study compares the effects of three backbone polymers, HDPE, HDPE/PP, PP, on the

\footnotetext{
Received date: October 14, 2016

Foundation item: National High-Tech Research and Development Program of China ("863" Program) (2013AA051402)

Corresponding author: Feng Yi, Ph. D., Professor, School of Materials Science and Engineering, Hefei University of Technology, Hefei 230009, P. R. China, Tel: 0086-551-62904715, E-mail: fyhfut@163.com

Copyright (C) 2017, Northwest Institute for Nonferrous Metal Research. Published by Elsevier BV. All rights reserved.
} 
dimensions and mechanical properties of $316 \mathrm{~L}$ green and sintered parts. Meanwhile, the removal of the three binders in the solvent debinding stage is also studied ${ }^{[12]}$.

\section{Experiment}

The 316L stainless steel powder used in the present study was obtained by a nitrogen atomization method from Titd powder, Changsha City Hunan Province, China. The chemical composition of the powder is shown in Table 1. And the pycnometer density of the powder is $7.9 \mathrm{~g} / \mathrm{cm}^{3}$, which can be used to determine the relative density of the sintered parts. The powder particle distribution is demonstrated in Table 2. It can be seen that a broad particle size distribution is favorable for efficient particle packing ${ }^{[13]}$, and the sizes of most particles are below $30 \mu \mathrm{m}$. Fig. 1 provides a scanning micrograph of $316 \mathrm{~L}$ stainless steel powders. All the particles are shown as approximately spherical well suited for powder flowability and dense particle packing in the injection molding stage.

The binder chosen in this experiment consists of three components: (1) paraffin wax (PW), (2) stearic acid (SA), (3) high density polyethylene (HDPE) and polypropylene (PP). PW $\left(54 \sim 56^{\circ} \mathrm{C}\right)$ was used as a filler to decrease the viscosity of the feedstock and increase the flowability of the feedstock, so it contributed to the feedstock filling the die cavity. The surfactant SA $\left(67 \sim 70^{\circ} \mathrm{C}\right)$ aims to enhance the adhesion between powder and binder, preventing the separation of powder and binder. HDPE $\left(133{ }^{\circ} \mathrm{C}\right)$ and PP $\left(164^{\circ} \mathrm{C}\right)$ based backbone polymer ensure the strength of the green parts from injection molding and maintain the shape of the compacts in the debinding stage.

The formulation of the binder based on HDPE, HDPE/PP, PP by mass percentage is given in Table 3. To obtain the feedstock, metal powder (93 wt $\%$ ) and binder (7 wt $\%$ ) were mixed in a double screw mixer. After fully mixing, the toothpaste-like viscous feedstock was carried out from mixer and cooled to the room temperature. The semisolid feedstock became hard and solid at room temperature. Finally, the homogenous feedstock was fed into the injection molding machine ${ }^{[14]}$.

In the injection molding stage, prepared feedstock was injected into the tensile specimen mold to understand the dimensions and mechanical properties of $316 \mathrm{~L}$ sintered parts by BOY $22 \mathrm{~A}$ injection molding machine. In order to improve the homogeneity of the feedstock, the feedstock was extruded by the screw, and then chopped into small pieces. The small pieces were again fed into the barrel and then injected into the die cavity to form the green parts. The green parts could be ejected by needle until they were solid enough. The geometric picture of the tensile bar in this study is shown in Fig.2.

Two stages were performed in the debinding process: solvent debinding and thermal debinding to remove the binder from the green parts. In the solvent debinding stage, the green parts were immersed in n-heptane solvent at $60{ }^{\circ} \mathrm{C}$ for $6 \mathrm{~h}$ to remove most of the PW and SA of the binder system $^{[15]}$. In the thermal debinding stage, to prevent deformation and dissolve the remaining binder, solvent debound parts were buried in the alumina powders by

Table 1 Powder chemical composition (wt\%)

\begin{tabular}{cccccccccc}
\hline Element & $\mathrm{Si}$ & $\mathrm{Cr}$ & $\mathrm{Ni}$ & $\mathrm{Mn}$ & $\mathrm{Mo}$ & $\mathrm{C}$ & $\mathrm{O}$ & & \\
\hline Content & 0.94 & 16.66 & 12.56 & 0.05 & 2.38 & 0.01 & 0.03 & Bal. \\
\hline
\end{tabular}

Table 2 Particle size distribution of 316L stainless steel powder

\begin{tabular}{ccccc}
\hline Particle size $/ \mu \mathrm{m}$ & $0 \sim 10$ & $10 \sim 20$ & $20 \sim 30$ & $30 \sim 40$ \\
\hline Volume fraction/\% & 33.45 & 44.93 & 17.78 & 3.86 \\
\hline
\end{tabular}

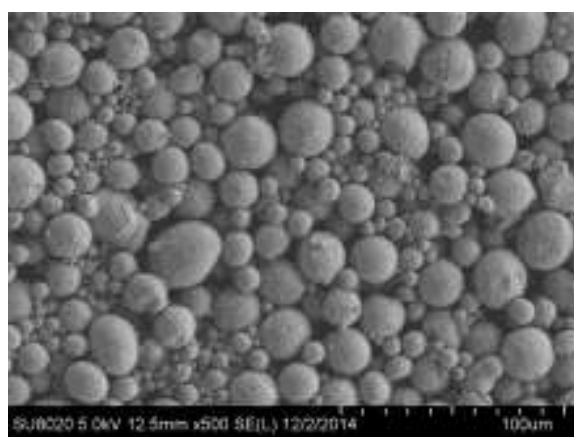

Fig. 1 SEM photograph of 316L stainless steel powders
Table 3 Formulation of binders in feedstock A, B, C (wt\%)

\begin{tabular}{ccccc}
\hline Binder & PW & SA & HDPE & PP \\
\hline A & 65 & 3 & 32 & $\ldots$ \\
B & 65 & 3 & 16 & 16 \\
C & 65 & 3 & $\ldots$ & 32 \\
\hline
\end{tabular}

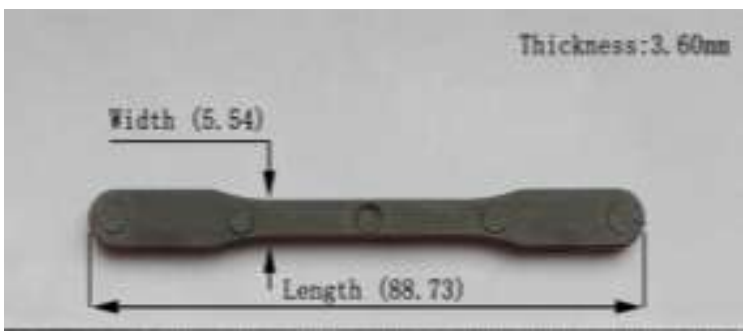

Fig. 2 Geometric picture of MIM tensile bar 
heating to $600{ }^{\circ} \mathrm{C}$ for $1 \mathrm{~h}$ in an argon atmosphere in high temperature tubular furnace ${ }^{[16]}$. Finally, the sintering process was executed in the same furnace to obtain a high relative density by heating to $1380^{\circ} \mathrm{C}$ for $3 \mathrm{~h}$ in $\operatorname{argon}$ atmosphere ${ }^{[17,18]}$ Then the furnace was cooled to room temperature.

\section{Results and Discussion}

\subsection{Determination of production process}

The melting and degradation temperatures of the components in the binder were measured by differential scanning calorimetry (DSC) and thermo gravimetry analysis (TGA). The temperature used for DSC ranged from $20^{\circ} \mathrm{C}$ to $200^{\circ} \mathrm{C}$ at $10^{\circ} \mathrm{C} / \mathrm{min}$ in a nitrogen atmosphere. And the experimental condition for TGA was the temperature heated from $20{ }^{\circ} \mathrm{C}$ to $600{ }^{\circ} \mathrm{C}$ at $10{ }^{\circ} \mathrm{C} / \mathrm{min}$ in a nitrogen atmosphere. The melting temperature resulting from DSC is useful to set the barrel and mold temperature in the injection molding stage. Fig. 3 provides the information about the DSC analyses of feedstocks A, B and C. It can be seen from Fig. 3 that the locations of the peaks in three feedstocks are consistent, which indicates that each component in the feedstocks is stable. And the three peaks at $56,116,143^{\circ} \mathrm{C}$ correspond to the melting temperatures of $\mathrm{PW}$ and $\mathrm{SA}$, HDPE, PP, respectively. Accordingly, the injection molding temperature should be set above $143{ }^{\circ} \mathrm{C}$, and the mold temperature should be set below $56^{\circ} \mathrm{C}$, which is the lowest temperature in binder from DSC results. Table 4 lists the injection molding parameters in detail for the tensile bar. In this investigation, the barrel temperature is set to $190{ }^{\circ} \mathrm{C}$ to improve the rheological properties of feedstock and decrease the degradation of the binder. The mold temperature is maintained below $56{ }^{\circ} \mathrm{C}$ by circulating cooling water. The holding pressure is set to $7.5 \mathrm{MPA}$ for 3 $\mathrm{s}$ for proper mold filling. In addition, the melting temperatures of backbone polymers in binder from DSC results are lower than the corresponding melt temperatures of HDPE and PP (133 and $\left.164{ }^{\circ} \mathrm{C}\right)$. The phenomenon of shifting of the melting temperature may be explained as follows: the mutual dissolution in the blending process restrains the crystallization of the backbone polymer, decreasing the melting temperature ${ }^{[19]}$.

TGA analyses of feedstocks A, B, C are displayed in Fig. 4, which contribute to determine the blending process and the thermal debinding process. It can be seen that $\mathrm{PW}$ and $\mathrm{SA}$ in the binder start degrading at $195^{\circ} \mathrm{C}$ until $330^{\circ} \mathrm{C}$, which indicates that the maximum injection molding temperature should be set below $195^{\circ} \mathrm{C}$. Then the backbone polymer starts evaporating at $330^{\circ} \mathrm{C}$ until the temperature reaches $493{ }^{\circ} \mathrm{C}$. Therefore, in the blending stage, to avoid PW and SA degrading, the feedstock was prepared by mixing the metal powder with HDPE and PP backbone polymers in a double screw mixer at $240{ }^{\circ} \mathrm{C}$ for $60 \mathrm{~min}$ at $40 \mathrm{r} / \mathrm{min}$. Then the PW and SA were added as filler and surfactant to

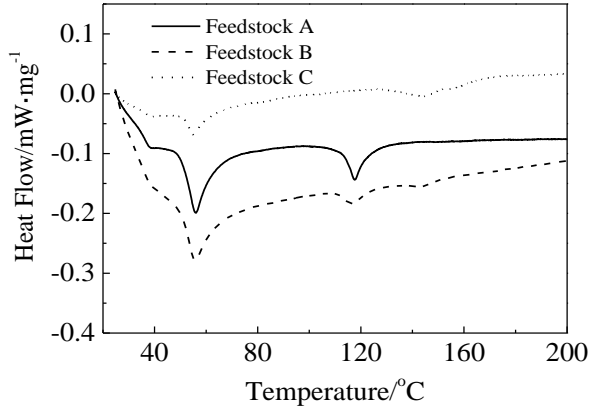

Fig. 3 DSC curves of feedstocks A, B, C

Table 4 Injection molding parameters of samples

Injection molding condition Injection molding parameter Zone 1 to Zone 3 temperature $/{ }^{\circ} \mathrm{C} \quad 190 / 180 / 170$

Nozzle temperature $/{ }^{\circ} \mathrm{C}$

190

Injection pressure/MPa

12

Injection speed $/ \mathrm{mm} \cdot \mathrm{s}^{-1}$

80

Holding pressure/MPa

Holding time/s

3

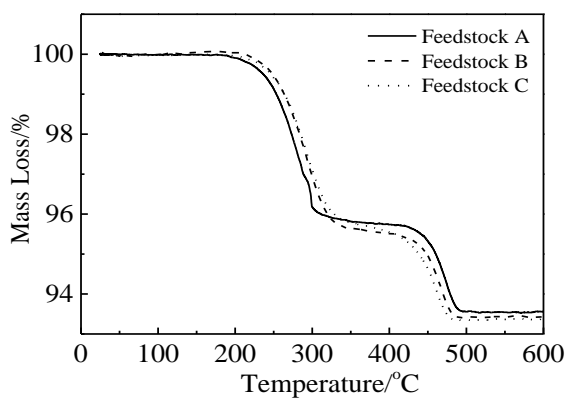

Fig. 4 Mass loss of feedstocks A, B and C

the mixture and blended at $190{ }^{\circ} \mathrm{C}$ for $30 \mathrm{~min}$ at $40 \mathrm{r} / \mathrm{min}$.

Meanwhile, in the thermal debinding stage, the temperature of thermal debinding should exceed $493^{\circ} \mathrm{C}$. In this study, the thermal debinding process was performed at $600{ }^{\circ} \mathrm{C}$. Table 5 lists the debinding and sintering conditions in detail. Finally, the total mass loss of feedstock is about $6.6 \%$ lower than the ratio before blending from TGA results This may be due to sampling error in experimentation during selection of specimen in TGA.

\subsection{Effect of three backbone polymers on the solvent debinding stage}

Solvent debinding is an important process that soluble part in binder is dissolved and open pore channels are formed. It can shorten heating and holding time of thermal debinding,

Table 5 Sequent debinding and sintering process conditions 


\begin{tabular}{cccc}
\hline $\begin{array}{c}\text { Sequence } \\
\text { No. }\end{array}$ & $\begin{array}{c}\text { Heating rate/ } \\
{ }^{\circ} \mathrm{C} \cdot \mathrm{min}^{-1}\end{array}$ & $\begin{array}{c}\text { Temperature/ } \\
{ }^{\circ} \mathrm{C}\end{array}$ & $\begin{array}{c}\text { Holding time/ } \\
\mathrm{min}\end{array}$ \\
\hline 1 & 5 & 300 & 30 \\
2 & 3 & 600 & 60 \\
3 & 5 & 900 & 30 \\
4 & 5 & 1380 & 180 \\
5 & 5 & 500 & - \\
6 & - & 50 & - \\
\hline
\end{tabular}

thereby reducing the total time of debinding. Meanwhile, the defect produced by solvent debinding is less than that by thermal debinding. In this study, the removal of binders based on three backbone polymers in the solvent debinding stage was also investigated in n-heptane solvent at $60^{\circ} \mathrm{C}$. The backbone polymer has an effect on the leaching rate of PW and SA in the binder. Fig.5 displays the percentage of PW and SA removed in the binders based on three backbone polymers with the extension of time. It can be seen that the percentage of removal of PW and SA gradually increases with the extension of time, but the rate of the removal gradually slows down and finally stabilizes. Furthermore, PW and SA in HDPE/PP binder are easier to

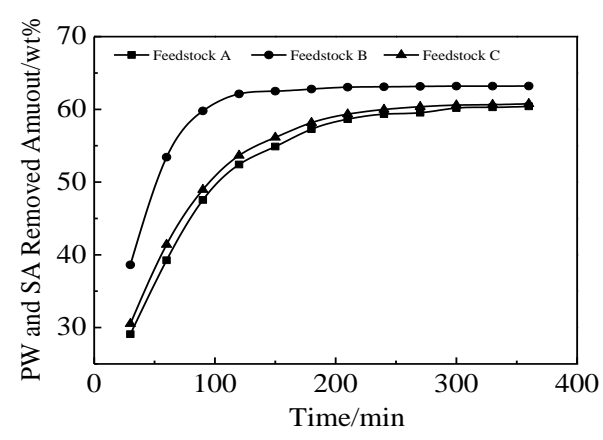

Fig.5 Amount of PW and SA removed in the binders during solvent debinding remove. Most of PW and SA in the binder close to $62.2 \%$ are removed in $2 \mathrm{~h}$, which is advantageous to optimize the solvent debinding process and shorten the time of solvent debinding.

Fig. 6 presents the micrograph of injection molding green part before and after solvent debinding at 60 for $6 \mathrm{~h}$ respectively. It can be clearly seen from Fig.6a that the binder surrounds the powder particles in the green part. Due to the removal of PW and SA in solvent debinding, the powder particles are not fully surrounded by binder and the open pore channels are formed in Fig.6b. The binder in Fig.6b is the backbone polymer and remains of PW and SA. The formation of open pore channels is favorable for the rapid removal of the remaining binder without cracking, blistering or swelling during subsequent thermal debinding stage. The residual binder forms a porous network to provide the strength of debound part.

\subsection{Dimensional analysis}

The dimensional stabilities of 316L stainless steel MIM compacts that correspond to feedstocks A, B, C are shown in Table 6. The dimensions of length, width and thickness measured by Venier caliper are further transformed into their respective shrinkage rate. It can be clearly seen from Table 6 that the dimensional stabilities of green parts and sintered parts are consistent: feedstock B performs better than others in terms of the dimensional stabilities of green parts and sintered parts. The reason is that HDPE and PP mixed in feedstock B have destroyed their own crystallinities, which leads to a lower shrinkage rate and decreases the deviation of the dimensions of the green parts and sintered parts. In addition, the three-dimensional stabilities of sintered parts with feedstock B are 46\%, 40\%, $20 \%$ better than those of feedstock C. To sum up, the three backbone polymers have different effects on the dimensional stability of $316 \mathrm{~L}$ stainless steel MIM parts. Consequently, the selection of the best backbone polymer for MIM is the basic condition for ensuring the dimensional stability of sintered parts.
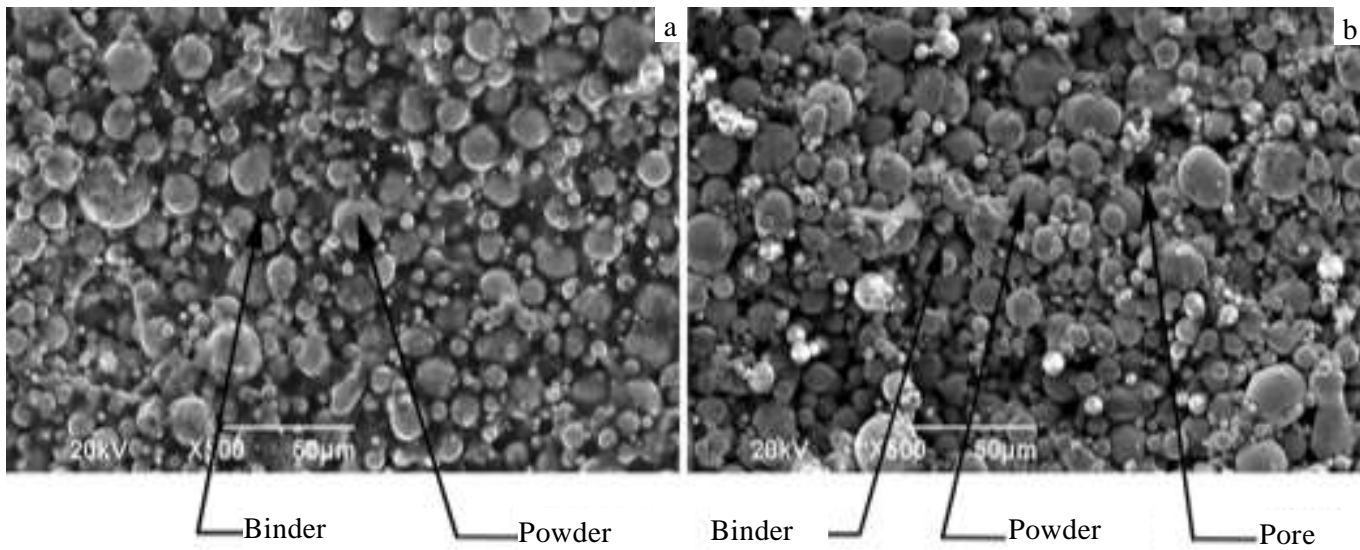

Fig. 6 SEM micrographs of green compact before debinding (a) and after solvent debinding (b) at $60^{\circ} \mathrm{C}$ for $6 \mathrm{~h}$ 
Table 6 Dimensional stabilities of green parts and sintered parts (shrinkage rate/\%)

\begin{tabular}{|c|c|c|c|c|c|c|c|}
\hline \multirow{2}{*}{ State } & & \multicolumn{2}{|c|}{ Feedstock A } & \multicolumn{2}{|c|}{ Feedstock B } & \multicolumn{2}{|c|}{ Feedstock C } \\
\hline & & Average & Standard deviation & Average & Standard deviation & Average & Standard deviation \\
\hline \multirow{3}{*}{ Green } & Length & 0.97 & 0.085 & 0.75 & 0.016 & 1.11 & 0.161 \\
\hline & Width & 2.97 & 0.247 & 2.67 & 0.220 & 3.19 & 0.262 \\
\hline & Thickness & 0.83 & 0.225 & 0.76 & 0.138 & 1.10 & 0.390 \\
\hline \multirow{3}{*}{ Sintered } & Length & 13.16 & 0.398 & 13.77 & 0.230 & 14.41 & 0.425 \\
\hline & Width & 16.48 & 0.705 & 15.65 & 0.525 & 16.65 & 0.873 \\
\hline & Thickness & 15.84 & 0.693 & 14.33 & 0.636 & 15.36 & 0.791 \\
\hline
\end{tabular}

\subsection{Mechanical properties analysis}

The density stabilities of sintered parts which correspond to feedstocks A, B, C are shown in Table 7. The density of sintered parts is measured by the Archimedes principle. The average density of the sintered parts produced by feedstock $\mathrm{B}$ is $7.28 \mathrm{~g} / \mathrm{cm}^{3}$, which is higher than those of the other feedstocks. Meanwhile, feedstock B also performs better in the density stability of sintered parts, and the standard deviation is only 0.020. For feedstocks $\mathrm{A}$ and $\mathrm{C}$ the corresponding values are 0.021 and 0.080 , respectively.

The HRB hardness of the sintered parts produced with feedstocks A, B, C show that feedstock B performs better than the other feedstocks in terms of the hardness stability of sintered parts. The hardness of sintered parts using feedstock $\mathrm{B}$ is also the largest of three feedstocks. In addition, the hardness and the density are closely related, so the results can also be predicted from the density of sintered parts.

The tensile test is carried out under DCS-5000 universal testing machine. The tensile strengths of sintered parts produced by using feedstocks A, B, C are 574, 579, 543 $\mathrm{MPa}$, respectively. As the results from the density and hardness, tensile strength of sintered parts from feedstock B is also the largest.

The pore structure and microstructure of sintered parts produced by feedstocks A, B, C are shown in Fig. 7. It can be seen from Fig.7a to $7 \mathrm{c}$ that the pore structure of feedstock

Table 7 Mechanical properties of 316L stainless steel sintered parts

\begin{tabular}{|c|c|c|c|c|c|c|}
\hline \multirow{2}{*}{ Properties } & \multicolumn{2}{|c|}{ Feedstock A } & \multicolumn{2}{|c|}{ Feedstock B } & \multicolumn{2}{|c|}{ Feedstock C } \\
\hline & Average & Standard deviation & Average & Standard deviation & Average & Standard deviation \\
\hline Density $/ \mathrm{g} \cdot \mathrm{cm}^{-3}$ & 7.26 & 0.021 & 7.28 & 0.020 & 7.25 & 0.080 \\
\hline Relative density $/ \%$ & 91.87 & 0.003 & 92.12 & 0.002 & 91.81 & 0.010 \\
\hline Hardness HRB & 70.4 & 2.5 & 72.3 & 1.3 & 58.3 & 6.8 \\
\hline Tensile strength/MPa & 574 & & 579 & & 543 & \\
\hline
\end{tabular}
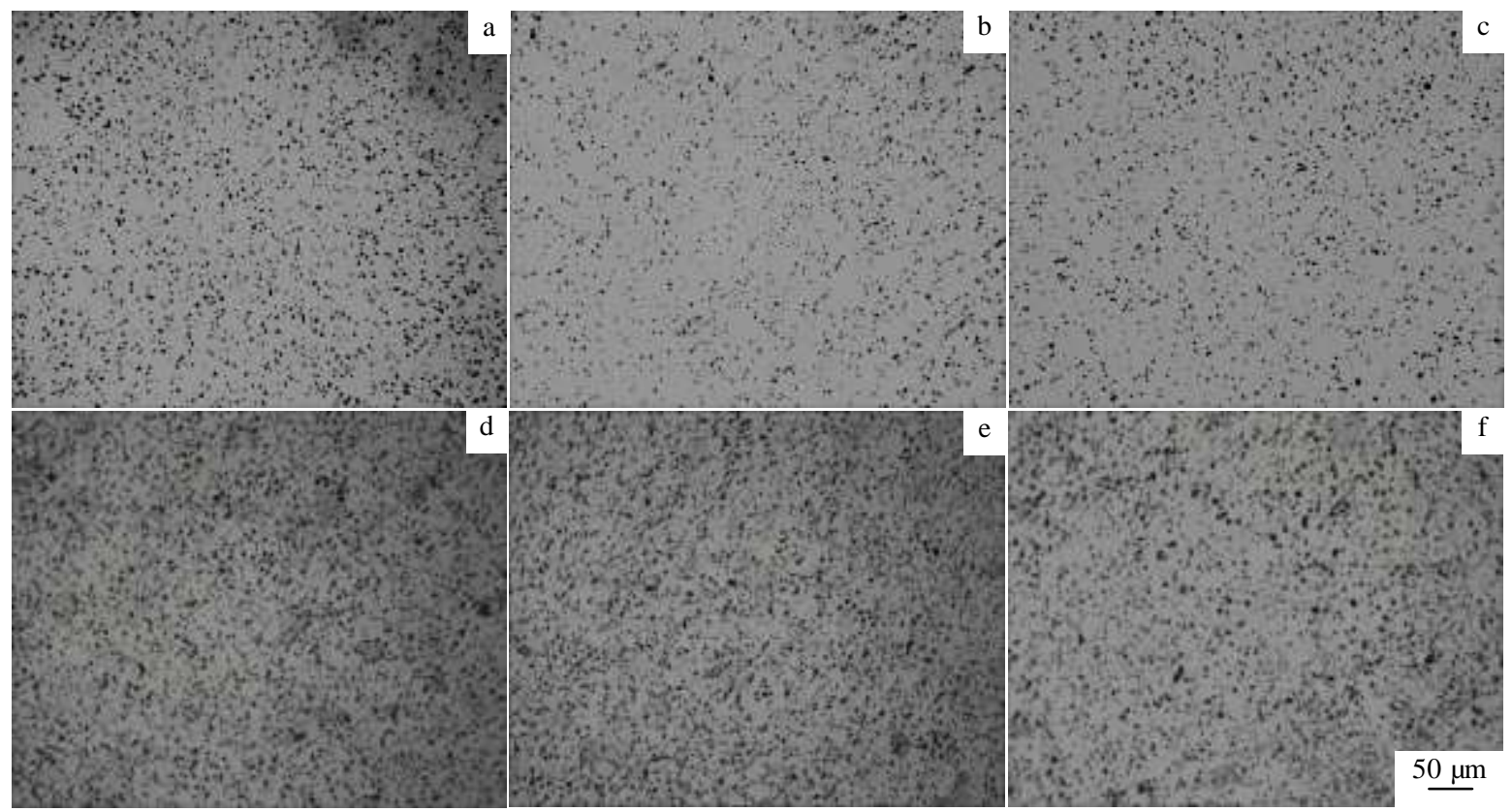

Fig. 7 Pore structures $(a \sim c)$ and microstructures (d f) of sintered parts with feedstocks A (a,d), B (b,e), and C (c,f) 
$\mathrm{B}$ is relatively less and regular, which leads to better dimensional stability and mechanical properties than others. From Fig. 7d to 7f, all the microstructures of sintered parts produced by three feedstocks contain duplex phase steel structure, i.e., $\alpha$ phase and $\gamma$ phase, which are typical for 316L stainless steel sintered parts. In this study, it can also be seen from the experimental results that the structure of twin crystallinity has little change with different backbone polymer during sintering stage.

\section{Conclusions}

1) The HDPE/PP backbone polymer shortens the time of solvent debinding and optimizes the solvent debinding process.

2) Use of a HDPE/PP backbone polymer performs better in terms of the dimensional stabilities of green parts and sintered parts than those of HDPE and PP. Threedimensional stabilities of sintered parts with HDPE/ PP are $46 \%, 40 \%, 20 \%$ better than those of PP.

3) The binder with HDPE/PP backbone polymer provides better density stability and hardness stability of $316 \mathrm{~L}$ stainless steel sintered parts than with HDPE and PP. Meanwhile, the binder with HDPE/PP backbone polymer improves the mechanical properties of sintered parts.

\section{References}

1 Piotter V, Beck M, Plewa K et al. Metal Powder Report[J], 2009, 64(9): 35

2 Kukla Christian G. International Journal of Forming Processes[J], 2001, 4: 253

3 Li Yimin, Huang Boyun, Qu Xuanhui et al. Rare Metal Materials and Engineering[J],1996, 25(1): 3 (in Chinese)
4 Meng Junhu, Loh Ngiap Hiang, Fu Gang et al. Journal of the European Ceramic Society[J], 2011, 31(6): 1049

5 Huang Mingshyan, Hsu Hungchuan. Journal of Materials Processing Technology[J], 2009, 209(15-16): 5527

6 Kong X, Barriere T, Gelin J C. Journal of Materials Processing Technology[J], 2012, 212(11): 2173

7 Liu L, Loh N H, Tay B Y et al. Materials Characterization[J], 2005, 54(3): 230

8 Hwang K S, Tsou T H. Metallurgical and Materials Transactions A[J], 1992, 23(10): 2775

9 Barriere T, Liu B, Gelin J C. Journal of Materials Processing Technology[J], 2003, 143-144: 636

10 Huang M S, Hsu H C. Powder Metallurgy[J], 2011, 54(3): 299

11 Guo Shibo, Qu Xuanhui, Duan Bohua et al. Rare Metal Materials and Engineering[J],2005, 34(6): 1124 (in Chinese)

12 Chen G, Wen G, Edmonds $\mathrm{N}$ et al. Powder Metallurgy[J], 2015, 58(3): 220

13 Sotomayor M E, Várez A, Levenfeld B. Powder Technology[J], 2010, 200(1-2): 30

14 Samanta S K, Chattopadhyay H, Godkhindi M M. Journal of Materials Processing Technology[J], 2011, 211(12): 2114

15 Yang Weiwen, Yang Kaiyuan, Wang Moochin et al. Ceramics International[J], 2003, 29(7): 745

16 Liu Xiangquan, Li Yimin, Yue Jianling et al. Transactions of Nonferrous Metals Society of China[J], 2008, 18(2): 278

17 Song J, Gelin J C, Barrière T et al. Journal of Materials Processing Technology[J], 2006, 177(1-3): 352

18 Fang Wei, He Xinbo, Zhang Ruijie et al. Transactions of Nonferrous Metals Society of China[J], 2015, 25(2): 552

19 Loh N H, Tor S B, Khor K A. Journal of Materials Processing Technology[J], 2001, 108(3): 398

\title{
不同热塑性蜡基粘接剂对 $316 \mathrm{~L}$ 注射成型件性能的影响
}

\author{
豆亚坤, 凤 仪, 黄晓晨, 汤 海, 丁冬冬, 田 沛, 夏 梦, 钱 刚, 张学斌 \\ (合肥工业大学, 安徽 合肥 230009)
}

\begin{abstract}
摘 要: 用金属注射成型方法研究 3 种热塑性蜡基粘接剂（高密度聚乙烯、高密度聚乙烯/聚丙烯、聚丙烯）对 $316 \mathrm{~L}$ 不锈钢尺寸稳定 性及机械性能的影响, 并对 3 种热塑性蜡基粘接剂溶剂脱脂过程进行了分析。结果表明, 用高密度聚乙烯/聚丙烯热塑性蜡基粘接剂得 到的 $316 \mathrm{~L}$ 不锈钢注射成型件尺寸稳定性及机械性能较好, 溶剂脱脂时间较短、效果较好, 其长、宽、高三维尺寸稳定性比聚丙烯热 塑性蜡基粘接剂得到的注射成型件分别高 46\%，40\%，20\%，密度、HRB 硬度和抗拉强度分别为 $7.28 \mathrm{~g} / \mathrm{cm}^{3} 、 723 \mathrm{MPa}$ 和 $579 \mathrm{MPa}$ 。 关键词：热塑性；金属注射成型；316L 不锈钢；机械性能
\end{abstract}

作者简介：豆亚坤，男，1989 年生，硕士，合肥工业大学材料科学与工程学院，安徽 合肥 230009, 电话：0551-62904715, E-mail: 465297690@qq.com 